\title{
La incertidumbre de las salas cinematográficas y el crecimiento del streaming ante la pandemia de la COVID-19
}

\section{The uncertainty of movie theaters and streaming in the face of the COVID-19 pandemic}

Isabel Lincoln Strange Reséndiz*

Universidad Anáhuac México

Av. Universidad Anáhuac núm. 46,

Col. Lomas Anáhuac, C. P. 52786, Huixquilucan,

Estado de México, México

Editor: Rogelio del Prado Flores

Fecha de recepción: 1 de julio de 2020

Fecha de aceptación: 21 de julio de 2020 isabelincoln@hotmail.com

https://orcid.org/0000-0002-6998-9123

https://doi.org/10.36105/stx.2020edespcovid-19.08

\section{RESUMEN}

Las salas cinematográficas enfrentan una crisis resultado de su cierre como consecuencia de la pandemia de la COVID-19 y de las medidas sanitarias tomadas por diversas naciones. Esta crisis se ve reflejada no solo en las pérdidas económicas sino también en la dinámica de la relación entre el espectador y el filme. En contraparte, las plataformas streaming han aumentado el número de suscriptores y, por lo tanto, sus ganancias. En el presente artículo se estudiarán las implicaciones de no asistencia a las salas y las ventajas que ofrece el streaming a los espectadores durante la pandemia. Para ello se recurrió al punto de vista de teóricos como P. Sorlin, G. Lipovetsky, C. Scolari, U. Eco.

Palabras clave: salas cinematográficas, streaming, hipermedialidad, pandemia, cultura.

* Doctora en Ciencias Políticas y Sociales, línea Comunicación y cultura, por la Facultad de Ciencias Políticas y Sociales de la unam. Profesora-Investigadora de la Licenciatura en Comunicación y el Doctorado en Investigación Comunicación de la Universidad Anáhuac México, Campus Norte. Tiene diversas publicaciones en libros y revistas, entre sus publicaciones se destacan: "La configuración de oriente a través de la representación histórica de Occidente en el cine: el caso de Las cuatro plumas" (Universidad La Salle, Xhimai, 2013), y "La masculinidad como producción discursiva y la feminidad como silencio" en El libro vacío y Los años falsos de Josefina Vicens (UAM Iztapalapa, 2017). Forma parte del Sistema Nacional de Investigadores, Nivel I. 


\section{ABSTRACT}

Movie theaters face a crisis resulting from their closure as a consequence of the COVID-19 pandemic and the sanitary measures taken by various nations. This crisis is reflected not only in the economic losses but also in the dynamics of the relationship between the viewer and the film. In counterpart, streaming platforms have increased the number of subscribers and, therefore, their earnings. This article will study the implications of not attending theaters and the advantages that streaming offers to viewers during the pandemic. The point of view of theorists such as P. Sorlin, G. Lipovetsky, C. Scolari, U. Eco served to study the subject.

Keywords: movie theaters, streaming, hypermedia, pandemic, culture.

La gente no puede tocarse ni verse; entonces, nos queda un poco de seducción, la peor, la de consumir.

Gilles Lipovetsky

La pandemia adelantó un filo de la ciencia ficción apocalíptica...

CARLOS SCOLARI

\section{INTRODUCCIÓN}

L

a crisis que presentan las diversas producciones audiovisuales, resultado de la incertidumbre generada por la contingencia CoviD-19, es un tema de estudio sumamente relevante. Varios complejos cinematográficos alrededor del mundo han cerrado sus puertas por lo que los estrenos de películas se postergaron. No obstante, y a pesar del trance, en todo el mundo ha aumentado el número de suscriptores de sistemas streaming. De tal manera que se asume que gran parte de las audiencias se han volcado por consumir productos audiovisuales en casa, tal como se observa en las cifras que se expondrán en las siguientes páginas.

La humanidad se enfrenta a un momento de coyuntura sobre la relación que mantiene con los medios de comunicación y la tecnología. La sociedad alrededor del mundo se ha visto obligada a sumergirse en el internet, resultado de la 
cuarentena (que lleva más de 120 días en algunas ciudades), e impuesta por las condiciones de home school y el home office. Asimismo, debido a las circunstancias del encierro, la humanidad se ha enfrentado a la necesidad de buscar formas de pasar el tiempo libre, por lo que se ha adentrado en el hiperespacio consumiendo contenidos audiovisuales, libros, paseos virtuales, etcétera.

Es este artículo se expone el estado de las salas y el streaming durante la emergencia sanitaria, a través de la recopilación de una serie de datos que han aparecido en diversos medios que dan cuenta del problema. Asimismo, para estudiar esta relación con el hiperespacio, que se ha visto aumentada por la pandemia, se recurrió al punto de vista de dos teóricos que ha profundizado en el tema de la cultura global en el tiempo de la hipermodernidad y la hipermediación: Gilles Lipovetsky $(1986,2011)$ y Carlos Scolari (2008). Por ende, la hipótesis del presente artículo se estructura de la siguiente manera: las salas de cine atraviesan por una crisis resultado de la pandemia de la covid-19. En contraparte, los sistemas de contenidos vía streaming han obtenido un mayor número de suscriptores. Si la pandemia se extiende por un periodo más prolongado y, en consecuencia, las salas cinematográficas se mantienen cerradas, éstas se enfrentan a la incertidumbre en torno a su funcionalidad como formas de entretenimiento. El objetivo del presente artículo consiste en analizar estas condiciones y estudiar cómo la hipermedialidad representa una solución, tanto para las películas como para el espectador que desea acceder a las mismas y que encuentra en las plataformas esa posibilidad.

\section{BREVE ESTADO DE LA CUESTIÓN EN TORNO}

\section{A LOS ESTUdiOS DE LA CULTURA GLOBAL}

La humanidad nunca se había enfrentado a una pandemia similar a la actual, en la que el encierro obliga a la conectividad a la web casi permanente. Si bien el tema es nuevo, algunos académicos y teóricos de la comunicación se han pronunciado al respecto. Gilles Lipovetsky ha otorgado entrevistas en las que expresa sus impresiones ante la crisis actual que, considera, ha sido provocada por "errores que han cometido los políticos", en la medida en la que han reforzado las fake news y han expuesto una evidente falta de profesionalismo. El teórico ha manifestado que el encierro expone las cualidades de la "sociedad híper individualista", en la que "el sujeto demanda una gran libertad para gobernar su vida". No obstante, 
la situación actual podría permitir la existencia futura de "una sociedad de mayor control" ante futuras amenazas (Lipovetsky, comunicación personal, 6 de abril de 2020).

El académico observa que el escenario del confinamiento es distinto para cada grupo social, una idea que se acerca a lo mencionado por Koselleck en torno a la noción de incertidumbre. Es decir, no todos los seres humanos son iguales ni viven las crisis de la misma manera. Lipovetsky declaró que la enseñanza de las humanidades es fundamental en la actualidad debido a que el humanismo y la democracia se conciben como ideales éticos que sostienen "el proyecto de la modernidad", más aún, en un momento como el que atraviesa la humanidad. En los meses de la contingencia, los políticos han hecho un llamado para aprovechar el tiempo en confinamiento, "para disfrutar de la cultura, de las cosas esenciales y profundas, pero en unas cuantas semanas, no puedes volverte receptivo al arte si no hay antes una formación, y ésta la recibimos en la escuela y en la universidad" (Lipovetsky, comunicación personal, 31 de mayo de 2020). Como bien observa el teórico, los artistas se enfrentan a una realidad adversa porque necesitan un público; en cambio, para los intelectuales, "este periodo de confinamiento ha sido de prosperidad [...] porque se tiene todo el día para trabajar tranquilos" (comunicación personal, 31 de mayo de 2020). Las condiciones del encierro dependen del grupo social.

Por otro lado, Carlos Scolari también se manifestó sobre la contingencia de la covid-19 y expuso: "ante la incertidumbre, los seres humanos necesitamos narrativas, queremos saber qué pasa. El homo sapiens necesita crear y necesita escuchar". Para el teórico, la crisis ha permitido a la humanidad acercarse a diversos tipos de narrativas y, también, "a las narrativas de la crisis del coronavirus". Han surgido diversos relatos en torno a la epidemia que pueden observarse a través de los medios de comunicación. No obstante, las narrativas sobre pandemia y a las realidades catastróficas y apocalípticas, no son nuevas para los espectadores, debido a que ya habían sido estructuradas por el cine y la literatura. Scolari ejemplifica esta cuestión: "en películas como 28 días después [...] Soy leyenda [...] Contagio"; incluso, apunta lo siguiente.

La pandemia adelantó un filo de la ciencia ficción apocalíptica, de tal manera que esto ya lo habíamos visto [...] los medios de comunicación, en su imaginario, buscan el encuadre, buscan imágenes que ya incluso forman parte de nuestra «enciclopedia», como diría Umberto Eco (Scolari, comunicación personal, 16 de mayo de 2020). 
Scolari reconoce que si bien las plataformas streaming tienen un modelo de negocio, esto no se reduce su importancia social y cultural: "Netflix revoluciona la forma de ver contenido audiovisual"; de hecho, subraya: "si no fuera por el internet, por la web y las malditas plataformas y aplicaciones, nos estaríamos todos tirando por el balcón. Debemos movernos en una realidad que vaya más allá de los apocalípticos e integrados; implica ir más allá de la tensión ocasionada por la pandemia" (Scolari, comunicación personal, 16 de mayo de 2020).

Las aproximaciones teóricas de Lipovetsky y Scolari, en torno a un tema que es contemporáneo al momento histórico que vivimos, son fundamentales para comprender la realidad de la crisis que se vive. Sin duda, nuestra visión en torno a la relación con el mundo del entretenimiento cambiará.

\section{METODOLOGÍA}

El impacto que la pandemia de la covid-19 ha ocasionado en la sociedad a nivel mundial es un tema al que las academias no se habían enfrentado con anterioridad. Por lo tanto, los métodos para estudiar las consecuencias de la misma en la sociedad son difíciles de estructurar. Además, si bien las publicaciones académicas solicitan el estudio de textos basados en una investigación de gabinete o de campo, no existen los antecedentes sobre una crisis similar a la actual ${ }^{1}$. Los investigadores de las ciencias sociales cuentan con una serie de objetos de estudio que están disponibles en las fuentes periodísticas que les permiten observar el contexto: cifras de enfermos, decesos, pérdidas económicas, caídas de mercados, etcétera. Es decir, conocen las cifras, comprenden y viven sus resultados día a día, pero el impacto que tendrá en un futuro sobre la sociedad en el ámbito internacional solo se comprende de manera empírica.

Existe una realidad contextual contemporánea relacionada con la pandemia y que afecta a dos industrias del entretenimiento, el cine y el streaming. El cierre de las salas cinematográficas y el crecimiento de compañías streaming. La metodología que se ocupó para este estudio surge principalmente a partir del análisis de las

1 Es importante considerar la pandemia de la gripa española en 1918 que causó la muerte de más de 50 millones de personas. Asimismo, la pandemia de la influenza H1N1, originada en México en el año 2009. No obstante, las condiciones de confinamiento de la actual pandemia son distintas que las anteriores, debido a las condiciones particulares del confinamiento y la interconectividad. 
notas periodísticas de diversos medios de comunicación; este análisis permitió identificar de qué manera las salas de cine se vieron afectadas por la contingencia de la covid-19, a partir del rastreo y registro de cifras y datos relacionadas con las pérdidas. Asimismo, la revisión llevó a observar el incremento en la contratación de sistemas streaming. Estos elementos determinaron la elección y la clasificación de las fuentes para el análisis.

A partir de lo mencionado, el objetivo del presente artículo consiste en determinar el impacto que la contingencia ha tenido en la industria del entretenimiento, específicamente en torno a las salas de cine y el streaming. Finalmente, para comprender las condiciones actuales de los aspectos mencionados de estos medios de comunicación, se recurrió al punto de vista de diversos teóricos, como Lipovetsky, Scolari, Sorlin, Eco. En este sentido, la teoría sirvió de "instrumento" o de "teoría usable", como la denomina Manuel Castells (2010), para analizar la temática. Es decir, permitió observar las circunstancias del cine y de la cultura global durante la pandemia.

\section{MARCO CONTEXTUAL}

El 31 de diciembre de 2020, China dio a conocer a la Organización Mundial de la Salud que existían en un hospital de la ciudad de Wuham 27 casos de personas infectadas por el virus SARS-CoV-2. El contagio se expandió rápidamente a diversas ciudades del mundo; en el mes de enero, más de 24 países tenían registrados casos de CoviD-19; para el mes de marzo, ya eran 100 países.

La emergencia sanitaria ha obligado a la humanidad a preguntarse de manera constante qué es lo que nos depara el futuro. En muchas ciudades del mundo no se sabe cuándo terminará el confinamiento, si se encontrará una vacuna, cuál será el costo de las vidas humanas. Según el reporte actualizado de The Washington Post del 30 de junio de 2020, en el mundo entero existen 10500000 casos de personas infectadas con el virus, y al menos 508000 muertes reportadas. Además, $B B C$ News en su sitio "Coronavirus: A visual guide to the economic impact", del 30 de junio de este año, anota que existe un importante riesgo de recesión económica internacional, debido a que la pandemia ha generado "una crisis como ninguna otra" (crisis like no other) (Jones, Palumbo y Brown). El impacto va desde el cierre de pequeños comercios hasta grandes industrias, la caída del precio del petróleo, el desplome de las bolsas internacionales. 
Asimismo, en el ámbito mundial, la sociedad se ha ajustado a la nueva normalidad $^{2}$, en la que el acceso a internet es esencial, ya que permite realizar actividades laborales, educativas y de entretenimiento, a pesar de que una parte de la población mundial no tiene acceso a la misma. La humanidad se ha visto invadida por la virtualidad, un término que actualmente determina las cualidades de las actividades cotidianas. Sin duda, los productos audiovisuales forman parte de la vida diaria, pensemos, por ejemplo en las noticias a las que se accede en televisión o en línea, los videos de YouTube, los TikTok, los minireportajes o minificciones que aparecen en las redes sociales, como Facebook o Twitter; además de todos los contenidos streaming a los que tenemos acceso a través de varias plataformas, y de géneros diversos, ya sea comedia, drama documental, series o películas, etcétera. Existe un crecimiento de los sistemas vía streaming resultado de la cuarentena, ya sea que se trate de Netflix, Paramount, Prime, HBO, Disney; la pandemia llevó a la sociedad a contratar estas plataformas como una distracción necesaria.

A partir del inicio de la epidemia y con el paso de las semanas y los meses subsecuentes, primero Wuhan y luego diversas ciudades del mundo, sometieron a su población a una emergencia sanitaria en la que se estableció el confinamiento en casa como una prioridad; el encierro ha implicado, a la vez, el cierre casi total de establecimientos de diversos giros: cines, teatros, museos, galerías, además de restaurantes, plazas comerciales y diversos tipos de comercios. Esto ha generado un fuerte impacto en la economía mundial y en diversas industrias, una de ellas es la del entretenimiento.

\section{MARCO TEÓRICO}

En el presente marco teórico es esencial exponer, primeramente y de manera breve, el significado de la palabra incertidumbre, debido a que su comprensión permite observar de manera más clara las condiciones que la realidad de la nueva normalidad implica para la sociedad. No obstante, es necesario acotar que si bien se busca dar una definición desde la teoría social, ésta no implica que este artículo se sustentará en el análisis de la incertidumbre per se. Como se apuntó en los

2 Sebastian Kurz, canciller austriaco, fue el primero el ocupar el término de nueva normalidad, durante la reapertura de espacios públicos el 21 de abril de 2020 en Austria (Bell, BBC). El concepto define la necesidad de establecer un distanciamiento humano espacial, dentro y fuera del hogar. La expresión ha sido ocupada por líderes de varios países. 
apartados anteriores y como se anota en el título de esta investigación, interesa analizar la producción cinematográfica, las salas de cine y el streaming ante la emergencia de la Covid-19.

La incertidumbre se define como la falta certeza sobre un tema que nos genera inquietud (RAE, 2020), y lleva a la sociedad a preguntarse por el futuro de la humanidad. Reinhart Koselleck, en su texto Futuro pasado. Para una semántica de los tiempos históricos (1993), señala que pensar en el futuro genera incertidumbre debido a que las posibilidades de lo que pueda suceder son muchas. Para el autor, definir el concepto de humanidad remite irremediablemente ante la incertidumbre debido a las posibilidades ambivalentes que implica universalidad del término (p. 238). Es decir, no todos los "hombres" son iguales, debido a que tienen diferentes creencias o situación socioeconómica distintas, pertenecen a diversos grupos sociales con variadas formas de vida.

Por lo tanto, reflexionar en una humanidad como un todo unido que funciona de la misma manera en todos los espacios sociales es una idea que nos puede generar incertidumbre y falta de certeza, justo como ha quedado de manifiesto con la pandemia y con el impacto que la misma ha tenido en diferentes aspectos de la vida íntima y social de los seres humanos.

La contingencia y el encierro llevó a la sociedad a sumergirse en lo que Lipovetsky anticipó desde la década de los años ochenta sobre mundo del consumo:

La profusión lujuriosa de sus productos, imágenes y servicios, con el hedonismo que induce, con su ambiente eufórico de tentación y proximidad, la sociedad de consumo [...] no se reduce al espectáculo de la acumulación; más exactamente se identifica con la sobre multiplicación de elecciones que la abundancia hace posible (Lipovetsky, 1986, p. 18).

Lipovetsky (2011) apunta que la nueva economía del consumo es cada vez grande y más rápida, con créditos más fáciles, con "más imágenes, más obras de arte, películas, series de televisión" (p. 35). Sin duda, las condiciones que impuso la CoviD-19 potenciaron las observaciones del autor en torno a la relación que las audiencias mantienen con los medios y, a la vez, con el consumo de productos de comunicación. Lipovetsky establece que un "capitalismo de hiperconsumismo que se distingue por esta hipertrophia de la esfera comercial" (2011, p. 37); en este sentido, los datos de las ventas en línea arrojan que los consumidores aumenta- 
ron durante la contingencia, contrario a lo esperado como resultado de la crisis económica internacional.

Observar la cultura y el mundo, a través de la estrecha relación que mantienen con los medios de comunicación, según señala Lipovetsky, es una idea que surgió a principios del siglo xx con el cine, con la producción de una serie de relatos que serían comprendidos en la mayor parte del mundo. Esto se traduce en lo que el autor comprende como la "cultura-mundo moderna" (2011, p. 55); el cine motivó la renovación permanente de los productos, lenguajes y consumos de masas. A la vez, señala que la televisión impuso el reinado de la imagen: "Con la televisión se imponen la 'aldea global' de McLuhan, el triunfo de la sociedad de la imagen y el hombre pantalla inaugurado por el cine" (p. 55). No obstante, Lipovetsky subraya que la humanidad se enfrenta a la revolución digital y a la proliferación de pantallas; la tecnología y el hiperespacio condicionan las formas de vida (2011).

La emergencia sanitaria nos ha obligado a pasar más tiempo conectados, de tal manera que pareciera que los contenidos se han multiplicado y que nuestra vida en esta época de pandemia está condicionada por el uso de la computadora. Empero, Lipovetsky se ha manifestado recientemente al respecto:

La cultura moderna ha aniquilado la tradición. Fundamentalmente esa es la cultura moderna, la destrucción de la tradición. La historia humana se ha descrito y contenido por la tradición. Antaño, no existía el deseo particular de cambiar el modo de vida, la gente comía, se vestía, bailaba y trabajaba de la misma manera que lo hicieron sus padres y sus abuelos. La modernidad transformó esa dinámica al colocar en el centro a la libertad y a la igualdad. Para mí esto es lo importante, una vez que la crisis termine o se equilibre, la gente continuará viajando a Túnez, China, Japón o a la playa, entonces, creo que la enfermedad CoviD-19, desgraciadamente, no nos hará más sabios (Lipovetsky, comunicación personal, 21 de mayo de 2020).

Por otro lado, Carlos Scolari en su libro Hipermediaciones. Elementos para una teoría de la comunicación digital interactiva (2008), señaló que el lugar tradicional del consumo de los medios de comunicación en el ámbito familiar está sufriendo transformaciones que influyen en los procesos de interpretación (p. 55). Este fenómeno se ha visto acelerado por la situación actual, en la que, como expone el autor: "la convergencia tecnológica: la tecnología digital se ha vuelto ubicua y ha transformado los procesos de producción, distribución y consumo de contenidos" (p. 60). Para Scolari, las tecnologías digitales afectan nuestro sistema de 
significación cultural; específicamente el uso de la web desplaza los límites entre lo público y lo privado, "superponiendo espacios individuales y colectivos" (p. 275). El confinamiento ha evidenciado la necesidad humana por acceder a espacios públicos. No obstante, dadas las circunstancias, los individuos se han visto obligados a crear comunidad y hacer encuentros colectivos de manera virtual, no solo porque lo exige la situación laboral o escolar, sino porque existe una necesidad de convivir en sociedad.

Las hipermediaciones se definen como una "trama de procesos de intercambio, producción y consumo simbólico que engloba una gran cantidad de sujetos, medios y lenguajes interconectados" (Scolari, p. 277) que funcionan a través del ciberespacio. Los medios tradicionales se encuentran confinados al espacio al que pertenecen, por lo que tienen que apostar a las hipermediación, una situación que estamos observando en la actual pandemia, incluso con otras formas de entretenimiento, como el teatro, ya que algunas puestas en escena se han transmitido, incluso, por redes sociales. De tal manera que, como lo apunta Scolari, tecnología, sociedad y cultura van de la mano.

En este sentido, la contingencia ha evidenciado la incertidumbre en torno a la relación del espectador con las salas cinematográficas y la pantalla grande. Es necesario reflexionar en la naturaleza tradicional del cine como medio de comunicación social. Es decir, se asiste a las salas en grupos, incluso aunque el espectador acuda sin acompañantes; la experiencia con el filmes individual; el rito de asistir a la sala en sociedad está arraigado a una forma de cultura. George Sadoul inicia su Historia del cine mundial (2004) exponiendo que el cine debe estudiarse como una forma de arte estrechamente ligada a la sociedad. Pierre Sorlin en su texto Sociología del cine. La apertura para la historia de mañana (1985), señaló lo siguiente:

Asistir -no asistir - a una función: esa elección es superior al objeto que se trata de ver; revela intereses, una actitud, relaciones con el medio que no se resumen en el acto - tan sencillo-de comprar una entrada y de sentarse; sin embargo, precisamente a partir de este objeto de tienden otras redes, se constituyen relaciones nuevas. Ir al cine es, indisociablemente, cumplir con un rito social e integrarse al conjunto de testigos de un espectáculo particular (p.11).

Si comprendemos la integración del cine al ciberespacio como una realidad resultado de la pandemia, es necesario considerar no solo en su naturaleza 
social y cultural, sino en sus cualidades narrativas y estéticas, a través de lo que Sorlin denomina como la "pantalla pequeña" (televisión). Umberto Eco, en Apocalípticos e integrados, apuntó que el cine se había habituado al relato televisivo y había adoptado posiciones encaminadas a otro tipo de narración (p. 337). En contraparte, lo que se observa desde hace algunas décadas es que la televisión adoptó formas narrativas del cine (Edgerton \& Jones, 2009); los elementos estéticos propios de dicha forma de arte se insertaron en las narrativas televisivas y del streaming. Como lo había anticipado Pierre Sorlin, se trate de pantalla grande o pequeña, ambos productos se insertan de la misma manera en nuestro aprendizaje intelectual. La diferencia consiste en que el cine proporciona, además, una experiencia social, cultural y artística gracias a la pantalla grande, el espacio de la sala cinematográfica y el resto de los elementos propios del medio.

\section{ANÁLISIS, DISCUSIÓN Y RESULTADOS:}

\section{LAS SALAS DE CINE Y EL ÉXITO DEL STREAMING}

La incertidumbre en torno a la forma tradicional de hacer y ver cine no surge con la contingencia de la covid-19 sino que, simplemente, se acrecienta, debido a que ésta tiene sus orígenes en el surgimiento y rápido crecimiento de las diversas plataformas streaming, su conquista de los espacios familiares e íntimos, y su rotunda victoria sobre otras formas de entretenimiento.

Es importante comprender que la situación actual pone en riesgo la naturaleza social del cine que, de antemano, parecía verse amenazada por el avance del streaming. No se debe olvidar que en años previos estas plataformas han ganado espacios de la producción cinematográfica, realizando cintas que han obtenido premios internacionales, como Roma (Alfonso Cuarón, 2018), Historia de un matrimonio (Marriage History, Noha Baumbach, 2019), o El irlandés (Martin Scorsese, 2019), por poner algunos ejemplos, todas co-producciones de Netflix y que se estrenaron a través del mismo sistema.

Sin duda, el confinamiento ha cambiado nuestras vidas pero esto no significa que la nueva normalidad sea permanente. Lipovetsky está convencido que somos capaces de regresar a la normalidad, a pesar de la incertidumbre que genera la situación actual: 
La gente ha estado confinada. Las actividades como ir al cine, al café, el restaurante y los viajes fueron reducidos, lo que provocó un discurso colectivo de que se viviría una revolución completa sobre el modo de vivir [...] Creo que es una completa ilusión, ya lo vimos en los Estados Unidos y en Francia, en cuanto abrieron las playas, la gente se precipitó, salió por todos lados tratando de hacer lo que siempre han hecho (Lipovetsky, comunicación personal, 21 de mayo de 2020).

La sensación de vivir "una revolución completa" como resultado de confinamiento es simplemente una ilusión, según anota Lipovetsky, a partir del comportamiento de la sociedad en varios países. Recordemos que en España, una vez que se levantó la cuarentena, la gente se precipitó a las calles, a los parques y a los lugares públicos, y se espera que dicho país finalice la fase de reapertura a finales de junio o principios de julio, lo que incluye cines y teatros (Semana, 2020).

La cuarentena ha obligado al cierre de salas de cine alrededor del mundo. Por ejemplo, en Gran Bretaña, la situación de la recuperación de los cines es incierta. A través del sitio web de la BBC, se dio a conocer que se analizan las condiciones actuales de las salas que se encuentran cerradas por la crisis (Aftab, 2020). Lo que se expone en dicho artículo es que el público sigue consumiendo películas pero ahora lo hace a través de la comodidad de su casa, lo que lleva a la gente a preguntarse si la cultura de asistir al cine se renovará o se perderá debido al aislamiento. En este sentido, es preocupante lo sucedido en China, una de las taquillas más importantes del mundo, ya que a mediados de marzo se intentó abrir nuevamente las salas pero, por exigencia del público, tuvieron que cerrarse nuevamente a los pocos días, ya que se argumentó que aún no existe la vacuna del virus y, por lo tanto, no deben permitirse asistencias masivas a eventos (Aftab, 2020).

Por otro lado, en Estados Unidos se lanzó en marzo de este año la película Onward, de Pixar, pero ésta solo se mantuvo una semana en cartelera, debido al cierre de la salas. Unas cuantas semanas después de su estreno, ésta fue incluida por algunos sistemas de streaming. Lo mismo aconteció con The Invisible Man (Leigh Wannell, 2020) y The Hunt (Craig Zobel, 2020), ambas de los estudios Universal, que estaban programadas para ser estrenadas en salas en el mes de mayo y que se lazaron a través de distintas plataformas.

La pregunta alrededor del mundo es cuál será la política que seguirán los cines una vez que termine la pandemia. Probablemente, como señala Lipovetsky, no habrá una revolución y regresaremos a nuestra forma de vida, por lo que debemos tomar el encierro con reservas. La reapertura de los cines en Texas se 
realizó con el 25\% de la capacidad, 24 espectadores por sala y se solicitó el uso cubrebocas, se cerraron pasillos y butacas para evitar el contacto y mantener la sana distancia (Kay, 2020). Asimismo, otras ciudades de la nación americana se han pronunciado por abrir los cines, como la cadena Georgia Theatre Company, con 22 salas en dicho estado, que tiene programado el estreno de Tenet de Christopher Nolan, que representó un inversión de 200 millones de dólares, y que se espera sea un éxito de reapertura. En nuestro país, las cadenas de cine proyectan abrir con la misma cinta.

Es oportuno apuntar que lo mismo sucedió con las salas de cine hace cien años con la gripe española que no solo provocó la muerte de más de 50 millones de personas, sino que también afectó a las industrias del entretenimiento. Una vez pasada esa pandemia, se practicaron políticas de reapertura de los cines; en Londres, por ejemplo, las salas eran ventiladas cada tres horas durante treinta minutos; se prohibió la entrada a los niños y se mostraban cintas informativas sobre los riesgo que conllevaba el no guardar la distancia en las salas (Aftab, 2020). En el caso actual, pareciera que la solución más acertada para algunas cintas es el estreno a través del streaming. Sin embargo, al momento de la redacción del presente artículo, todo parece aún incierto.

Las pérdidas monetarias para los cines son importantes. En Estados Unidos, AMC perdió 2.18 mil millones de dólares en su último trimestre, una disminución del $22 \%$. Por otro lado, Cinemark, que opera 6132 pantallas en dicho país y en Latinoamérica, tendrá una pérdida de aproximadamente 59 millones de dólares durante el último trimestre (Barnes, 2020). En nuestro país, Fernando de Fuentes, presidente de la Cámara Nacional de la Industria Cinematográfica, señaló que cada mes de dejan de vender 30 millones de boletos, lo que significa pérdidas de 1500 millones de pesos (Ochoa, 2020). Como vemos, a partir de los ejemplos anotados, el panorama para las salas de cine es poco alentador.

Lo anterior, lleva a una pregunta esencial y que se relaciona con el futuro de la relación del espectador con el filme, más que con las salas en sí. Como se apuntó en el apartado de Marco teórico, la hipermediación parece ser la respuesta para en medio frente a la crisis que enfrenta. El propio Sorlin anticipó el conflicto que crearían en el espectador las múltiples pantallas: "hemos crecido, cualquiera que sea nuestra edad, con la pantalla grande y la pequeña, rara vez somos capaces de definir la parte que corresponde al cine o a la televisión en la constitución de nuestro bagaje intelectual" (p.13). Es decir, asimilamos de la misma manera el discurso audiovisual de uno u otro medio. Eco, también había anticipado las cualidades de 
la narración televisiva contemporánea, al observar la posibilidad de relacionar "ciertos episodios de la experiencia televisiva con otros episodios del cine actual, aun distinguiendo las posibilidades de la narración televisiva de la cinematográfica que provoca y finge, con mucha mayor consecuencia y cálculo estético" (Eco, p. 310). Las producciones audiovisuales vía streaming establecen un vínculo, desde el punto de vista estético, con el cine; cuentan con el "cálculo estético" del que hablaba Umberto Eco y que es resultado, también, de la evolución de los propios medios de comunicación y de los mismos espectadores.

Es necesario reflexionar que a través de los medios de comunicación tradicionales, los espectadores se insertan en una dinámica de interacción social y cultural, como sucede con la televisión, el streaming y el cine. En este sentido: "La transmedialidad juega un papel central en la construcción del mundo ficcional en términos de lo que llamamos la Hyperdiégesis, o la creación un vasto y detallado mundo narrativo espacial, y sólo una fracción de ese espacio es directamente visto o se encuentra con el texto" (Evans, 2011, p. 18). Los relatos transmedia proveen partes del texto que no están disponibles a través de los contenidos que aparecen en los medios tradicionales; además, ofrecen una visión ficcional complementaria que permite el acceso a otros mundos ficcionales. La contingencia ha provocado la especulación en torno al contenido de películas y series que estaban programadas para ser estrenadas en los meses de la cuarentena (Stranger Things 4, The Handmaid's Tale 4, Tenet, etcétera), por lo que el público se ha volcado en contenidos transmedia que puedan dar cuenta de la historia que desean conocer. Implica la creación de un sistema de intercambio cultural-incluso artístico-que tiene un impacto en este contexto histórico. De tal manera que el transmedia parece ser una salida afortunada para las producciones o estrenos que se quedaron pendientes.

La pandemia puso de manifiesto la estandarización de un tipo de vida; como señala Lipovetsky en torno la "era del todo-pantalla", en la que las imágenes y la información están ligadas al uso de la red y de la comunicación interactiva (2011, p. 56). El aumento de consumidores de sistemas streaming se hizo evidente los dos primeros trimestres del 2020, como resultado del encierro. La compañía Netflix obtuvo ganancias de $165 \%$ en el segundo trimestre del año, un aumento del 25\% y el margen se operación creció el 22,1\%; estas cifras son resultado de un crecimiento de los suscriptores y, en consecuencia, de los ingresos (Dinero, 2020). También disparó las ganancias de Amazon Prime Video, Disney, HBO y otras plataformas (El País). 
El encierro obligó a las personas a insertarse en el mundo del audiovisual. Por ejemplo, Estados Unidos es el principal mercado de Netflix, con 158,33 millones de suscriptores, con ganancias anuales de 20156 millones de dólares (Statista, 2020). Según un estudio realizado por la plataforma Hulu, el 90\% de los estadounidenses, entre los 13 y los 54 años de edad, usa algún sistema streaming y establece una diferenciación entres los tipos de uso de los mismos: el primero es el "terapéutico" con un $43 \%$ de usuarios que recurren al medio en busca de obtener algún tipo de ayuda o reflexión; el "clásico", con un $23 \%$, se aproxima a las condiciones de recepción de la televisión; los "indulgentes", con un $21 \%$, son los que consumen los productos de manera desenfrenada y, finalmente, los "entendidos" cuentan con un $13 \%$ y son aquellos que desean contenidos inteligentes (Ruiz, 2020).

Es fundamental observar que la contingencia ha favorecido al streaming desplazando, incluso, a la televisión. En Estados Unidos, un $32 \%$ de los hogares ya no cuenta con televisión tradicional; y el $45 \%$ de los usuarios de televisión de paga cancelaron sus suscripciones durante la crisis como resultado de la falta de contenidos. Asimismo, el jefe de marketing de la empresa Roku, Mathew Anderson, señaló que existe una tendencia a dejar la televisión por cable debido a la pandemia y la falta de contenidos nuevos (Ruiz).

El encierro parece haber establecido una nueva norma en torno a los requerimientos técnicos de vida, misma que Lipovetsky anticipó:

Para encontrar soluciones a los grandes problemas de la vida, la salud, el envejecimiento, la comunicación, en todas partes se recurre a la técnica [...] La técnica no es ya una simple parte de la civilización es la lógica organizadora de nuestras culturas y de todas las dimensiones de la vida, sea económica o social, cultural o individual [...] Universalismo técnico, idéntico en todos los lugares, que unifica los modos de obrar y de vivir [...] (2011, p. 47).

En el confinamiento, los seres humanos se vieron en la necesidad de adquirir conocimientos relacionados con el uso de diversos tipos de computadoras; pensemos en madres realizando home school con sus hijos de primaria o profesores impartiendo sesiones de clases virtuales. Asimismo, pareciera que los usuarios de redes sociales se convirtieron en expertos del uso de lo audiovisual y su producción; es decir, "dominaron la técnica", empleando una idea de Lipovetsky. 


\section{CONCLUSIONES}

Como se observa en el presente artículo existe, sin duda, una nueva realidad impulsada por la pandemia en torno a las salas cinematográficas y al streaming. Sin embargo, los resultados están, finalmente, condicionados por la incertidumbre. Como resultado del confinamiento, el escenario social para que las plataformas streaming capten a un mayor número de suscriptores es evidente pero, dada la crisis económica, estas circunstancias pueden llegar a modificarse. Podemos anticipar, a partir de las reflexiones vertidas por teóricos como Lipovetsky, que si bien los seres humanos son incapaces de cambiar su realidad y que las cosas volverán a la normalidad, nos encontramos en un momento de coyuntura y de reflexión que nos lleva a preguntarnos sobre cuáles serán las condiciones de nuestra realidad contemporánea a partir de la epidemia. A la fecha, finales de julio de 2020 , diversas farmacéuticas en varios países han declarado tener la vacuna contra el virus, como Pfizer y BioNTech (Griffin, 2020), y que se está realizando la fase final de las pruebas. No obstante, si los resultados son positivos, pueden pasar varios meses para que la vacuna se distribuya alrededor del mundo.

Las implicaciones de la nueva normalidad son varias y los cambios que la sociedad ha implementado han impacto directamente al cine más que a cualquier otro medio de comunicación, debido a que la interacción con el mismo implica, forzosamente, salir de casa. A partir de los hallazgos observados, es probable que los filmes deban no proyectarse sino transmitirse a través de sistemas streaming y no proyectarse en las pantallas grandes. Asimismo, podemos anticipar que las realizaciones cinematográficas tendrán que recurrir cada vez más a la virtualidad para poder sobrellevar las condiciones de la nueva normalidad. Finalmente, que los sistemas streaming se encuentran en la incertidumbre, ya que si bien los dos primeros trimestres del 2020 implicaron ganancias importantes para los mismos, aunque la económica mundial, golpeada por la emergencia sanitaria, no ofrece garantías a las empresas.

Independientemente de si la pandemia de la covid-19 cambiará o no nuestra forma de relacionarnos como sociedad, la incertidumbre existe. Este artículo hace una reflexión, a partir de lo mencionado en las notas informativas de los medios de comunicación, en torno a la crisis por la que atraviesa el cine en este momento. 


\section{RE FERENCIAS}

Aftab, K. (2020, 6 de abril). Why cinemas will bounce back from the Coronovirus crisis. BBC Culture. https://www.bbc.com/culture/article/20200403-why-cinemas-willbounce-back-from-the-coronavirus-crisis

Barnes, B. (2020, 9 de junio). AMC Says 'Almost All' U.S. Theaters Will Reopen in July. The New York Times. https://www.nytimes.com/2020/06/09/business/coronavirus-amc-movie-theaters-reopening.html

Bell, B. (2020, 6 de abril). "Austria opens bars and restaurants in may". BBC News. https:// www.bbc.com/news/topics/cgg43703kxzt/sebastian-kurz

Dinero (2020, 16 de junio). Ganancias de Netflix se dispararon $165 \%$ y nombra a nuevo CEO. Dinero. Resultados financieros. https://www.dinero.com/inversionistas/articulo/ cuanto-gano-netflix-en-el-segundo-trimestre-de-2020/292876

Edgerton, G., \& Jones, J. P. (2009). The Essential HBO Reade. [El lector esencial de HBO]. Universidad de Kentuky.

El País. (2020, 27 de abril). Los ganadores empresariales de la pandemia son teconológicos. https://cincodias.elpais.com/cincodias/2020/04/26/companias/ 1587926357. 776058.html

Evans, E. (2011). Transmedia Television. Audiences, New Media and Daily Life. [Televisión transmedia: audiencias, nuevos medios y vida diaria]. Routledge.

Griffin, R. (2020, 24 de julio). Pfizer y BioNTech inician ensayo de fase final para vacuna experimental contra el CoVID-19. El Financiero. https://www.elfinanciero.com.mx/ salud/pfizer-y-biontech-inician-ensayo-de-fase-final-para-vacuna-experimental-contra-el-covid-19

Jones, L., Palumbo, D., \& Brown. (2020, 30 de junio). Coronavirus: A visual guide to the economic impact. BBC News. https://www.bbc.com/news/business-51706225

Kay, J. (2020, 12 de mayo). First Texas cinemas reopening in US after coronavirus lockdown. Screendayly. https://www.screendaily.com/new, s/first-texas-cinemas-reopening-in-us-after-coronavirus-lockdown/5149529.article

Koselleck, R. (1993). Futuro pasado. Para una semántica de los tiempos históricos. (Roberto Smilg, trad.). Paidós.

Lipovetsky, G. (1986). La era del vacío. Ensayos sobre el individualismo contemporáneo. (J. Vinyoli y M. Perdanx, trad.). Anagrama.

Lipovetsky, G. (2011). El occidente globalizado. Un debate sobre la cultura planetaria. (Antonio Prometeo Moya, trad.). Anagrama.

Ochoa, C. (2020, 13 de junio). Cines reescriben su historia para sobrevivir a la mala película del CoviD-19. Milenio. https://www.milenio.com/negocios/ante-coronavirus-cines-se-adaptan-para-sobrevivir 
Pellicer, M. (2020, 16 de mayo). Carlos Scolari: “Hay que equilibrar la mirada crítica contra las plataformas digitales" [Entrevista a Carlos Sacolari]. https://miquelpellicer. com/2020/05/carlos-scolari-transmedia-entrevista/

Pita, E. (2020, 6 de abril). Gilles Lipovetsky, filósofo: "Los medios deberían reducir la dimensión emocional de la información del coronavirus: genera pánico" [Entrevista a Gilles Lipovetsky]. Expansión. Fuera de serie. https://www.expansion.com/fueradeserie/personajes/2020/04/06/5e81c54de5fdea1c1a8b45a6.html

Real Academia de Lengua Española. (2020). Definición de incertidumbre. https://dle.rae. es/certidumbre

Ruíz de Elvira, A. (2020, 23 de julio). Entender a los espectadores de la generación del 'streaming'. El País. https://elpais.com/television/2020-07-23/entender-a-los-espectadores-de-la-generacion-del-streaming.html

Sadoul, G. (2004). Historia del cine mundial. (José Agustín Mahieu, trad.). Siglo XXI.

Scolari, C. (2008). Hipermediaciones. Elementos para una teoría de la comunicación digital interactiva. Gedisa.

Semana (202 0, 6 de junio). Nuestro espejo: Italia y España, ejemplo para la reapertura de Latinoamérica. Semana. https://www.semana.com/mundo/articulo/coronavirus-italia-y-espana-ejemplo-para-la-reapertura-de-lationamerica/676535

Sorlin, P. (1985). Sociología del cine. La apertura para la historia de mañana. (Juan José Utrilla, trad.). Fondo de Cultura Económica.

Statista (2020,15 de mayo). Evolución de los ingresos anuales de Netflix a nivel mundial de 2002 a 2019 (en millones de dólares). Statista. https://es.statista.com/estadisticas/639161/ingresos-anuales-de-netflix/

The Washington Post (2020, 30 de junio). Mapping the worldwide spread of Coronavirus. [Mapeando la expansión del Coronavirus alrededor del mundo]. https://www. washingtonpost.com/graphics/2020/world/mapping-spread-new-coronavirus/?itid=sn_coronavirus_3

Velasco, M. (2020, 31 de mayo). Gilles Lipovetsky: "Es un imperativo el buen vivir material, pero debe ser respetuoso con el medio ambiente" [entrevista a Gilles Lipovetsky]. Infobae Cultura. https://www.infobae.com/cultura/2020/06/10/gilles-lipovetsky-es-un-imperativo-el-buen-vivir-material-pero-debe-ser-respetuoso-con-el-medio-ambiente/ 